\title{
Genome-Wide Analysis of Genes Encoding Methionine-Rich Proteins in Arabidopsis and Soybean Suggesting Their Roles in the Adaptation of Plants to Abiotic Stress
}

\author{
Ha Duc Chu, ${ }^{1}$ Quynh Ngoc Le, ${ }^{1,2}$ Huy Quang Nguyen, ${ }^{2}$ and Dung Tien Le ${ }^{1}$ \\ ${ }^{1}$ National Key Laboratory of Plant and Cell Technology, Agricultural Genetics Institute, Vietnam Academy of Agricultural Sciences, \\ Pham Van Dong Road, Hanoi, Vietnam \\ ${ }^{2}$ Department of Biochemistry and Plant Physiology, Faculty of Biology, VNU-University of Science, \\ Vietnam National University-Hanoi, Nguyen Trai Street, Hanoi, Vietnam
}

Correspondence should be addressed to Dung Tien Le; research@letiendung.info

Received 12 June 2016; Accepted 19 July 2016

Academic Editor: Xuan H. Cao

Copyright (c) $2016 \mathrm{Ha}$ Duc Chu et al. This is an open access article distributed under the Creative Commons Attribution License, which permits unrestricted use, distribution, and reproduction in any medium, provided the original work is properly cited.

Oxidation and reduction of methionine (Met) play important roles in scavenging reactive oxygen species (ROS) and signaling in living organisms. To understand the impacts of Met oxidation and reduction in plants during stress, we surveyed the genomes of Arabidopsis and soybean (Glycine max L.) for genes encoding Met-rich proteins (MRPs). We found 121 and 213 genes encoding MRPs in Arabidopsis and soybean, respectively. Gene annotation indicated that those with known function are involved in vital cellular processes such as transcriptional control, calcium signaling, protein modification, and metal transport. Next, we analyzed the transcript levels of MRP-coding genes under normal and stress conditions. We found that 57 AtMRPs were responsive either to drought or to high salinity stress in Arabidopsis; 35 GmMRPs were responsive to drought in the leaf of late vegetative or early reproductive stages of soybean. Among the MRP genes with a known function, the majority of the abiotic stress-responsive genes are involved in transcription control and calcium signaling. Finally, Arabidopsis plant which overexpressed an MRP-coding gene, whose transcripts were downregulated by abiotic stress, was more sensitive to paraquat than the control. Taken together, our report indicates that MRPs participate in various vital processes of plants under normal and stress conditions.

\section{Introduction}

Under elevated ROS levels, free and protein-based Met are converted to methionine sulfoxide (MetO) which occurs in a diastereomeric mixture of methionine-S-sulfoxide (Met$S-\mathrm{O}$ ) and methionine- $R$-sulfoxide (Met- $R-\mathrm{O}$ ) [1]. Oxidation of Met was reported to occur in various signaling proteins, thereby modulating their functions [1-9]. For example, calmodulin (CAM), a versatile protein involved in various signaling pathways, including ROS homeostasis in Arabidopsis [10], is well known to have its methionine residue oxidation linked to protein dysfunction [11] and loss of protein stability [12]. Nevertheless, efforts to systematically identify all the proteins whose methionine residues are susceptible to oxidation yielded limited results due to the lack of viable tools, including an antibody specific to methionine sulfoxide
[13-16]. Recently, Tarrago and colleagues proposed an affinity chromatography approach employing methionine sulfoxide reductase (MSR) to catch interacting partners. Using AtMSRB1 as bait, the authors isolated 24 interacting partners functioning in photosynthesis, translation, and protection against oxidative stress from Arabidopsis. The authors found a preference of proteins with higher Met content to bind to the bait, becoming isolated by this approach [17]. Quite recently, Jacques et al. used a newly developed technique called COFRADIC [18] for proteome-wide identification of Met oxidation sites in Arabidopsis proteins. Their work revealed 500 sites of Met oxidation in 400 proteins of the plant [19].

Organisms evolved two enzyme families to repair oxidized Met in proteins: methionine-S-sulfoxide reductase (MSRA) to reduce Met-S-O and methionine-R-sulfoxide 
reductase (MSRB) to reduce Met-R-O. In vivo modulation of MSR activities has been reported in yeast $[20,21]$, fruit flies [22], and mammals [23], which in turn affected their tolerance to oxidative stress and lifespan. In plants, Romero et al. demonstrated the role of Arabidopsis plastidial MSRAs in the defense against oxidative stress [24]. In another study, transgenic tomato overexpressing pepper MSR gene CaMSRB2 was found to protect against oxidative stress and Phytophthora pathogen infection [25]. Very recently, the role of Arabidopsis cytosolic AtMSRB7 and AtMSRB8 in conferring tolerance to oxidative stress was also demonstrated [26], whereas overexpression of AtMSRB1 and AtMSRB2 in plastids did not improve tolerance to high light stress [27].

A number of studies have documented the role of enhancing expression of MSR-coding gene(s) in conferring stress tolerance to plants, but still little is known about the MSR targets which provide such tolerance. A notable study by Laugier et al. provided indirect evidence that Arabidopsis plastidial MSRBs confer tolerance to high light stress by acting on cpSRP43 and cpSRP54, thereby maintaining the integrity of the photosystem antenna under environmental constraints [28]. Another recent study by Lee and colleagues on Arabidopsis cytosolic MSRB indicated that the enzyme conferred stress tolerance to the plants by acting on two glutathione transferases, GSTF2 and GSTF3 [29]. This study also suggested a list of potential substrates of AtMSRB7. Despite the fact that oxidation and reduction of Met residues in CAM and other calcium signaling proteins were experimentally verified to be involved in regulating the protein's functions $[2-4,11,12]$, they were not found among the potential candidates acquired by either the affinity chromatography approach or approaches that employed mass spectroscopy $[17,19,29]$. This line of evidence offers opportunity to argue that either the current approaches for proteome-wide identification of MSR targets pose technical limitations or the oxidation and reduction of Met in many proteins like CAM happen transiently, such that these techniques were unable to help in identifying them. To provide a complementary approach to identify possible targets of MSR in plants, in this work, we surveyed genomes of two dicots, Arabidopsis and soybean, to obtain polypeptides of more than 95 residues in length with more than $6 \%$ of Met in their sequences. We analyzed these genes in terms of functions, transcriptional responsiveness to stresses, and the conservation of Met residues in HMM profiles (a hidden Markov model-based profile of amino acid residues in a protein domain). A list of genes transcriptionally responsive to stresses with an HMM profile containing highly conserved Met is provided for experimental confirmation by the research community.

\section{Materials and Methods}

2.1. Materials. Unless otherwise stated, Arabidopsis thaliana studied in this work is Columbia ecotype and soybean is of Williams 82 cultivar. Arabidopsis seed overexpressing MRP gene(s) was obtained from Arabidopsis FOX line library (RIKEN BioResource Center, Tsukuba, Japan). Briefly, full length cDNA of Arabidopsis were placed under the control of $35 \mathrm{~S}$ promoter and then inserted into a hygromycin-resistant plasmid. The plasmids were then transformed into Arabidopsis plants using flower-dipping technique. The development of FOX line library and the line carrying At3g55240 were previously reported [30].

2.2. Growth of Arabidopsis and Stress Treatment. Arabidopsis seeds were germinated on $0.5 \mathrm{x}$ MS media with or without antibiotics. At 2 weeks old the plants were transferred to soil and allowed to grow at $24 \pm 2^{\circ} \mathrm{C}$ with 16 -hour lighting. For paraquat leaf disc assay, 3-week-old rosette leaves were excised and placed on paraquat solutions of various concentrations; after keeping in the dark for 1 hour, the plates were kept at $24^{\circ} \mathrm{C}$ for 24 hours. The experiments were done in triplicate; each replicate consists of 3 plants.

2.3. Computational Analyses. Protein sequences were downloaded from the PHYTOZOME database (http://www.phytozome.net/) and searched for proteins of 95 residues or more whose sequences contain $6 \%$ or more Met by using a java script. The cutoff value for protein length was chosen after consulting reports on the distribution of protein sizes [31, 32]. Genes satisfying these conditions were named Met-rich proteins (MRP): AtMRPs for genes from Arabidopsis and GmMRPs for genes from soybean. Genes encoding MRPs were classified into functional categories using MAPMAN [33]. The PFAM database (http://pfam.xfam.org/) was used to search for HMM profiles as well as possible protein domains.

To obtain transcription levels, microarray data from previous studies were mined, including datasets for Arabidopsis under drought and salinity stress $[34,35]$ and soybean under experimental drought conditions [36]. In that study, for drought treatment of Arabidopsis, 2-week-old plants were transferred to soil and allowed to grow for one more week; the 3-week-old plants were then withheld from watering for 10 days. After the tenth day, rosette leaves were collected from both well-watered and drought-stressed plants, frozen in liquid nitrogen, and stored at $-80^{\circ} \mathrm{C}$ until RNA extraction. For high salinity treatment, 10-day-old plants grown on GM media were transferred onto $0.5 \mathrm{x}$ MS plates without sucrose, containing either $0 \mathrm{mM}$ (untreated) or $200 \mathrm{mM} \mathrm{NaCl}$ and maintained for a period of $24 \mathrm{~h}$. Samples were collected in three biological replicates, frozen in liquid nitrogen, and stored at $-80^{\circ} \mathrm{C}$ until used for RNA extraction. The drought treatment of soybean plants and data acquisition was described previously [36]. Data analyses were performed with functions integrated in MS EXCEL.

\section{Results and Discussions}

3.1. Occurrence of Genes Encoding MRPs in Arabidopsis and Soybean. An exhaustive search of genes encoding proteins longer than 95 residues and containing 6\% Met or more resulted in 121 and 213 genes from Arabidopsis and soybean genomes, respectively. Functions of about $50 \%$ of those genes were not known. RNA transcription, protein modification, and calcium signaling were the three major functional categories of the MRPs analyzed (Figure 1), indicating the important roles of MRP-coding genes in overall cellular function. Smaller categories include RNA processing and metal 


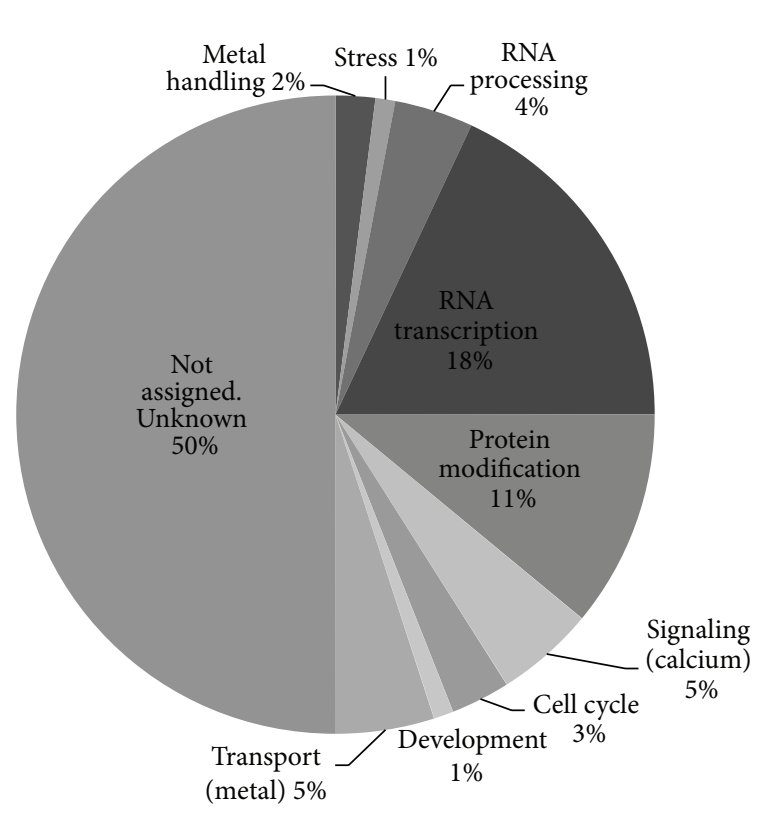

(a)

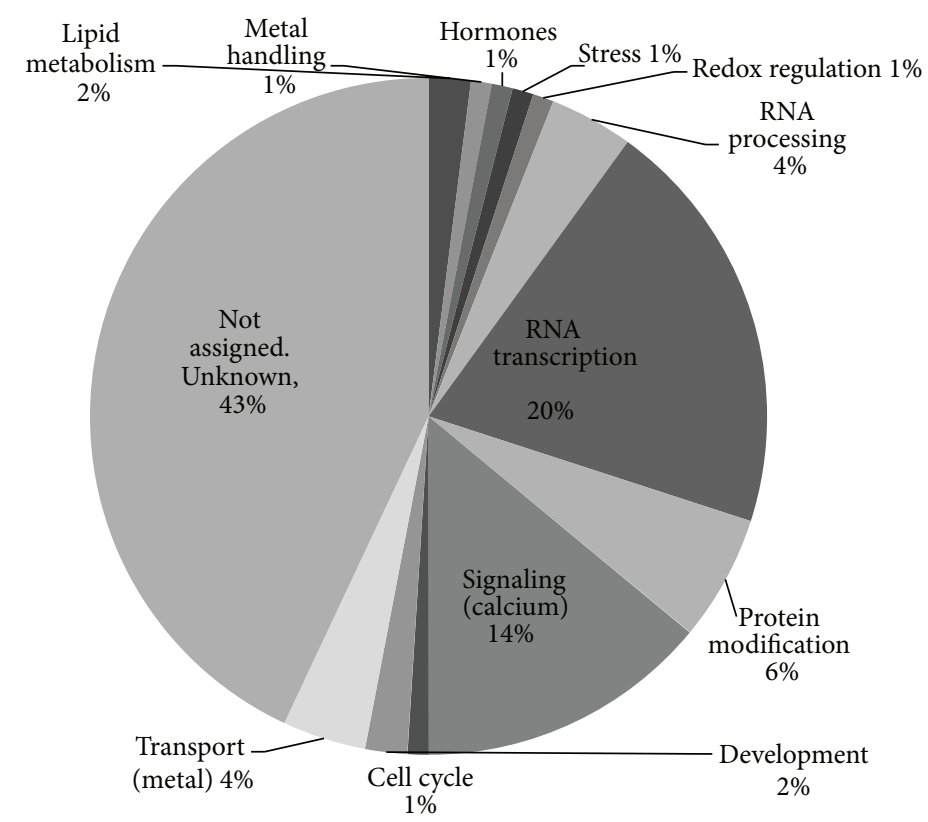

(b)

FIgURE 1: Distribution of genes encoding MRPs into various biological processes in Arabidopsis (a) and soybean (b).

transport. Specifically, there were 20 and 44 MRP-coding genes functioning in RNA transcription in Arabidopsis and soybean, respectively, making it the most abundant category. The second most abundant category was protein modification, of which 12 and 15 genes were found in Arabidopsis and soybean, respectively. There were $6 \mathrm{MRP}$-coding genes of Arabidopsis functioning in calcium signaling, whereas 31 MRP-coding genes found in soybean genome belonged to this category. Among MRP-coding genes identified, soybean has 10 genes distributed in 4 unique categories that were not presented in Arabidopsis, namely, lipid metabolism (4 genes), amino acid metabolism (2 genes), hormones (2 genes), and redox regulation ( 2 genes).

3.2. Stress-Responsive MRP-Coding Genes in Arabidopsis. To obtain MRP-coding genes transcriptionally responsive to abiotic stresses, our published microarray data of drought and high salinity treatments of wild type Arabidopsis [34, 35] were analyzed and data mining was performed. Of the 121 Arabidopsis genes, expression data of 108 genes were available (Table S1 in the Supplementary Material available online at http://dx.doi.org/10.1155/2016/5427062). Further analyses indicated that 23 and 16 genes were induced and repressed more than 2-fold, respectively, by drought treatment. Under treatment by high salinity, 11 and 17 genes were induced and repressed more than 2 -fold, respectively. Among droughtand salt-responsive MRP-coding genes, several genes were previously confirmed to be stress-inducible, of which the expressions of the 10 genes were responsive to both drought and high salinity (Table 1). Most of the genes were responsive to both stressors' code for plant-specific proteins. AT4G33467, encoding an unknown protein, was the most induced gene. Its transcript level was upregulated more than 330-fold by drought. Among stress-repressed genes, AT3G55240 was the most downregulated. Its transcript level was repressed by 60 - and 26-fold under drought and high salinity, respectively. The function of this gene is not yet known; however, it was reported that overexpression of this gene in Arabidopsis led to the phenotype "pseudo-etiolation in light" [30].

3.3. Stress-Responsive MRP-Coding Genes in Soybean. To identify stress-responsive genes among MRP-coding genes, we performed data mining with the microarray experiments conducted earlier. In these experiments, drought treatments were carried out by withholding water. Leaves of V6 (vegetative) and R2 (reproductive) stages were collected and microarray analyses performed as reported [36]. Transcript levels of all 213 MRP-coding genes were obtained, of which 11 were repressed and 12 genes were induced under drought in V6 trifolia. In reproductive leaves (R2 trifolia), drought treatment induced 24 genes, whereas only 6 genes were repressed (Table S2). A total of 13 MRP-coding genes were found to be transcriptionally responsive to drought in both vegetative and reproductive-stage leaves (Table 2 ). The gene Glyma04g37040, which encodes a calmodulin-binding protein CML38, was the most induced gene by drought and its transcript levels were induced 40- and 15-fold in R2 and V6 trifolia, respectively. The most repressed gene by drought was Glyma02g10620, encoding a 98-residue protein of unknown function whose transcript levels were repressed 44- and 4fold in V6 and R2 trifolia, respectively.

3.4. Common Stress-Responsive MRP-Coding Genes in Arabidopsis and Soybean. In Arabidopsis, 7 AtMRPs were upregulated and 3 other AtMRPs were downregulated under both 
TABLE 1: Genes encoding AtMRPs whose expression levels were responsive to both drought and high salinity.

\begin{tabular}{|c|c|c|c|c|c|c|c|c|}
\hline \multirow{2}{*}{ Number } & \multirow{2}{*}{ Locus IDs } & \multirow{2}{*}{ Met (\%) } & \multirow{2}{*}{ Length (a.a.) } & \multicolumn{2}{|c|}{ Drought versus untreated $^{1}$} & \multicolumn{2}{|c|}{ Salinity versus untreated $^{2}$} & \multirow{2}{*}{ Gene descriptions } \\
\hline & & & & Fold change $^{3}$ & $q$-value & Fold change $^{3}$ & $q$-value & \\
\hline 1 & AT1G32560 & 6.02 & 134 & 135.33 & 0.002 & 3.31 & 0.005 & $\begin{array}{l}\text { LEA group } 1 \text { domain-containing } \\
\text { protein }\end{array}$ \\
\hline 2 & AT1G33860 & 8.55 & 153 & 2.37 & 0.092 & 2.16 & 0.003 & Unknown protein \\
\hline 3 & AT3G55240 & 6.12 & 95 & -60.29 & 0.007 & -26.88 & 0.001 & $\begin{array}{l}\text { Overexpression leads to } \\
\text { pseudo-etiolation in light } \\
\text { phenotype }\end{array}$ \\
\hline 4 & AT3G59900 & 6.20 & 130 & 10.70 & 0.011 & -2.57 & 0.015 & $\begin{array}{c}\text { (ARGOS); unknown protein } \\
\text { [AT3G59900.1] }\end{array}$ \\
\hline 5 & AT3G62090 & 6.38 & 346 & 64.56 & 0.020 & 2.28 & 0.002 & $\begin{array}{c}\text { PHYTOCHROME } \\
\text { INTERACTING FACTOR } \\
\text { 3-LIKE } 2\end{array}$ \\
\hline 6 & AT4G12334 & 6.25 & 113 & -9.79 & 0.003 & -3.04 & 0.005 & $\begin{array}{c}\text { Pseudogene of cytochrome P450 } \\
\text { family protein }\end{array}$ \\
\hline 7 & AT4G33467 & 8.91 & 102 & 337.51 & 0.002 & 6.16 & 0.023 & Unknown protein [AT4G33467.1] \\
\hline 8 & AT4G34590 & 6.33 & 159 & 8.26 & 0.004 & 3.27 & 0.002 & $\begin{array}{l}\text { GBF6 (A. thaliana BASIC } \\
\text { LEUCINE-ZIPPER 11) }\end{array}$ \\
\hline 9 & AT5G42325 & 6.03 & 233 & 2.70 & 0.028 & 2.45 & 0.049 & $\begin{array}{l}\text { Transcription elongation } \\
\text { factor-related }\end{array}$ \\
\hline 10 & AT5G67390 & 7.43 & 176 & -4.17 & 0.015 & -4.15 & 0.001 & $\begin{array}{l}\text { Similar to unknown proteins } \\
\text { (TAIR:AT1G69360.1) }\end{array}$ \\
\hline
\end{tabular}

${ }^{1}$ Two-week-old plants were transferred to soil and allowed to grow for an additional week; the plants were then withheld from watering for $10 \mathrm{days}$. After $10 \mathrm{~d}$ of water with holding, rosette leaves were collected from both well watered and drought-stressed plants in three biological replicates, frozen in liquid nitrogen, and stored at $-80^{\circ} \mathrm{C}$ until used for RNA extraction [35]. ${ }^{2} 10$-day-old plants grown on GM media were transferred onto $0.5 \times$ MS plates without sucrose, containing either $0 \mathrm{mM}$ (control) or $200 \mathrm{mM} \mathrm{NaCl}$, and maintained for a period of $24 \mathrm{~h}$. Three independent experiments were performed for each condition. The samples were collected as three biological replicates (10 plants/replicate), frozen in liquid nitrogen, and stored at $-80^{\circ} \mathrm{C}$ until used for RNA extraction [34]. ${ }^{3}$ Stress responsive AtMRPs were defined as genes encoding MRP whose expression levels were induced or repressed 2-fold or more with an FDR corrected $p$ value of less than 0.05 .

TABLE 2: Genes encoding GmMRPs whose expression is responsive to drought stress in V6 and R2 leaves.

\begin{tabular}{|c|c|c|c|c|c|c|c|c|c|}
\hline \multirow{2}{*}{ Number } & \multirow{2}{*}{ Glyma ID } & \multirow{2}{*}{$\begin{array}{l}\text { Met } \\
(\%)\end{array}$} & \multirow{2}{*}{ Length (a.a.) } & \multicolumn{2}{|c|}{ V6 trifolia } & \multicolumn{2}{|c|}{ R2 trifolia } & \multirow{2}{*}{ Gene descriptions } & \multirow{2}{*}{$\begin{array}{c}\text { Arabidopsis } \\
\text { homologs }\end{array}$} \\
\hline & & & & Fold change & $q$-value & Fold change & $q$-value & & \\
\hline 1 & Glyma01g15910 & 8.08 & 100 & 3.63 & 0.045 & 4.96 & 0.042 & No original description & \\
\hline 2 & Glyma01g15930 & 6.56 & 458 & -20.34 & 0.007 & -3.87 & 0.015 & UNE10; transcription factor & AT4G00050 \\
\hline 3 & Glyma02g10620 & 7.22 & 98 & -44.63 & 0.007 & -4.04 & 0.053 & $\begin{array}{l}\text { Overexpression leads to } \\
\text { pseudo-etiolation in light }\end{array}$ & AT3G55240 \\
\hline 4 & Glyma03g32740 & 6.04 & 481 & -2.19 & 0.007 & -2.02 & 0.030 & $\begin{array}{l}\text { PIF1, PIL5; transcription } \\
\text { factor }\end{array}$ & AT2G20180 \\
\hline 5 & Glyma04g37040 & 7.91 & 140 & 15.03 & 0.012 & 40.08 & 0.005 & $\begin{array}{l}\text { Calmodulin-binding } \\
\text { protein CML38 }\end{array}$ & AT1G76650 \\
\hline 6 & Glyma06g39910 & 10.34 & 117 & 3.12 & 0.067 & 4.14 & 0.013 & $\begin{array}{l}\text { Calcium-binding EF hand } \\
\text { family protein }\end{array}$ & AT4G27280 \\
\hline 7 & Glyma10g30380 & 7.43 & 149 & 7.53 & 0.013 & 5.27 & 0.026 & $\begin{array}{c}\text { calmodulin } 5 \text {; calcium ion } \\
\text { binding }\end{array}$ & AT2G27030 \\
\hline 8 & Glyma15g05510 & 7.37 & 96 & 2.93 & 0.025 & 2.41 & 0.023 & No original description & \\
\hline 9 & Glyma16g02510 & 7.26 & 125 & 2.05 & 0.028 & 4.63 & 0.023 & $\begin{array}{l}\text { Calcium-binding protein, } \\
\text { putative }\end{array}$ & AT2G46600 \\
\hline 10 & Glyma19g43580 & 6.7 & 210 & -2.01 & 0.160 & 2.42 & 0.078 & $\begin{array}{c}\text { GIF, GIF1, AN3 } \\
\text { (ANGUSITFOLIA3) }\end{array}$ & AT5G28640 \\
\hline 11 & Glyma20g00780 & 6.69 & 285 & -3.03 & 0.046 & -2.36 & 0.027 & $\begin{array}{l}\text { Contains homeodomain } \\
\text { (InterPro:IPR009057) }\end{array}$ & AT1G10820 \\
\hline 12 & Glyma20g22280 & 6.59 & 426 & 2.25 & 0.046 & 2.99 & 0.056 & $\begin{array}{l}\text { PIF3, POC1, PAP3, } \\
\text { transcription factor }\end{array}$ & AT1G09530 \\
\hline 13 & Glyma20g36730 & 7.89 & 153 & 3.06 & 0.042 & 2.29 & 0.129 & $\begin{array}{c}\text { calmodulin } 5 \text {; calcium ion } \\
\text { binding }\end{array}$ & AT2G27030 \\
\hline
\end{tabular}




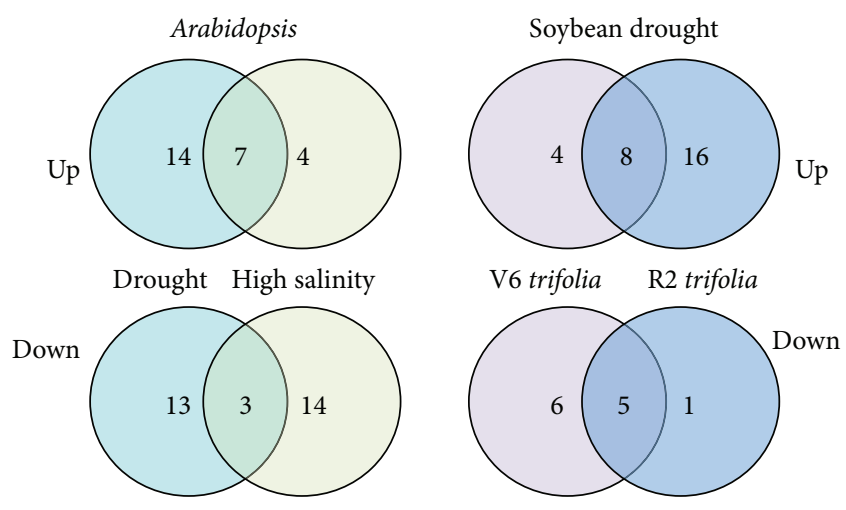

(a)

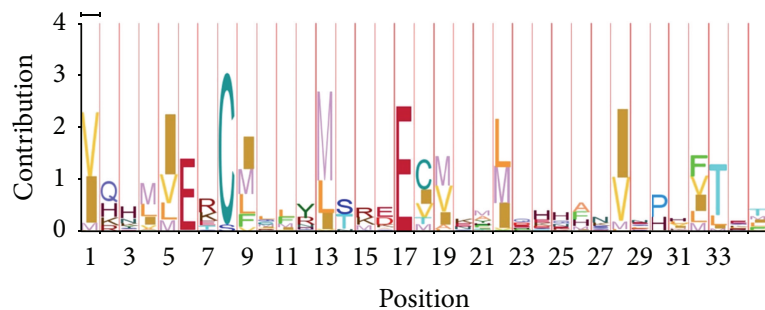

(b)

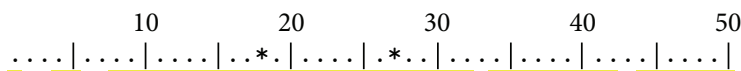

$$
\begin{aligned}
& \text { AT3G55240.1 MADSS--SASYIHMVQHMIEKCLIFHMSKEECVEALSKHANITPVITSTV } 48 \\
& \text { Glyma02g10620.1 MGESSNSSASYIHMVQHMIEKCLIFHMSKEECMEALSKHANIKPVITSTV } 50 \\
& \begin{array}{llll}
60 & 70 & 80 & 90
\end{array} \\
& \ldots|\ldots| \ldots|\ldots| \ldots|\ldots| \ldots|\ldots| \ldots|\ldots| \ldots
\end{aligned}
$$

(c)

Figure 2: Venn diagram analyses of the expression of MRP-coding genes in Arabidopsis and soybean under abiotic stresses (a), and HMM profile of Arabidopsis and soybean homologs share common responsiveness to drought (b) and their peptide sequence alignment (c).

drought and high salinity. In soybean drought, 8 and 5 GmMRPs were up- or downregulated, respectively, in both V6 and R2 trifolia (Figure 2(a)). Among 6 AtMRPs encoding calcium signaling proteins, three genes were transcriptionally responsive to either drought or salt (Table S1). At the same time, $14 \mathrm{GmMRPs}$ encoding calmodulin-like proteins were transcriptionally responsive to drought in either V6 or R2 trifolia or both. This data suggested that calcium signaling plays an important role in the plant's signaling during abiotic stress exposure. In light of previous studies, it is very likely that Met oxidation and reduction of calmodulin may also contribute significantly to the plant's signaling response to abiotic stresses. A number of AtMRPs and GmMRPs encoding transcription factors were also responsive to abiotic stresses in Arabidopsis and soybean (Tables 1 and 2), indicating the involvement of the MRPs in the important cellular activities.

Further analysis of stress-responsive MRP-coding genes identified a gene coding for a plant-specific protein that has homologs in both Arabidopsis (AT3G55240) and soybean (Glyma02g10620). These genes encoded highly homologous proteins ( $>70 \%$ identity) of about 100 amino acid residues that share an HMM profile with several conserved Met residues in the $\mathrm{N}$-terminal (Figures 2(b) and 2(c)). In a previous study, it was found that overexpression of this gene in Arabidopsis caused a phenotype of pseudo-etiolation in light or leaf bleaching [30], although how such phenotype occurred was not explained. When Arabidopsis was transformed with an RNAi construct to downregulate this gene, most of the transgenic plants died at a very early stage and the plants that survived did not show any reduction in the transcription levels, suggesting a vital function of this gene
[30]. To determine if the gene At3g55240 is involved in redox stress responses, we acquired the overexpressor line from the Arabidopsis FOX line library (RIKEN BioResource Center) and analyzed them. Growing of the plants on MS media and soil confirmed the pseudo-etiolation phenotype (Figure 3(a)). When treated with paraquat in a leaf disc assay, the overexpressor line exhibited higher sensitivity than the wild type control (Figure 3(b)), suggesting the gene may be involved in mediating redox stress responses. This gene and its soybean homolog were both repressed under abiotic stress; thus, increasing its expression may not provide benefit under stress.

3.5. Stress-Responsive cis-Elements of the MRPs' Promoter. To provide further evidence of the stress-responsiveness of MRP-coding genes, we searched for the presence of known stress-responsive cis-elements in the promoters of the genes in Arabidopsis $1 \mathrm{kbs}$ upstream of the transcriptional start sites. We found that promoters of AtMRPs contain 23, 26, and 16 cis-elements of ABRE, MYBR, and MYCR, respectively. On average there are 0.54 cis-elements per AtMRP and 0.86 cis-elements for each stress-responsive AtMRP, indicating a slight enrichment of stress-responsive cis-elements among drought- and/or salt-responsive AtMRPs.

3.6. Subcellular Localization of MRPs. Chloroplast and mitochondria are the two types of cellular organelles which generate high levels of ROS. Thus, identification of MRPs localizing to these organelles may shed light on their functions. Using amino acid sequences of AtMRPs and the prediction tools such as TargetP [37], pSORT [38], and CELLO [39], we 


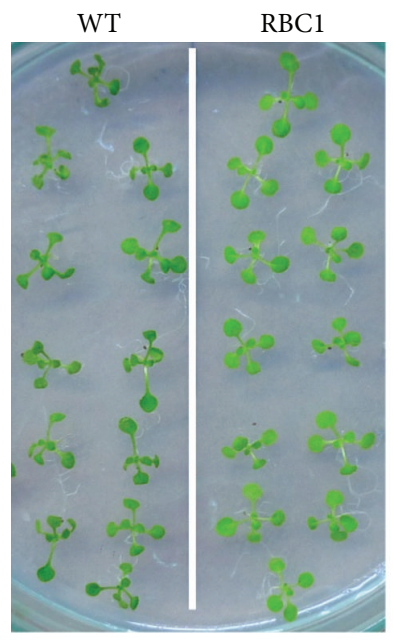

12 days old

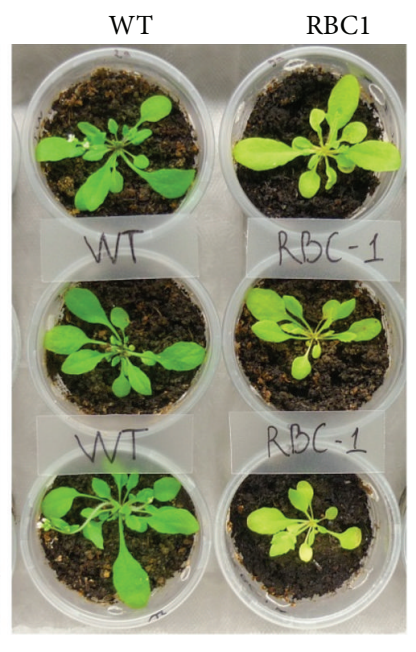

5 weeks old

(a)

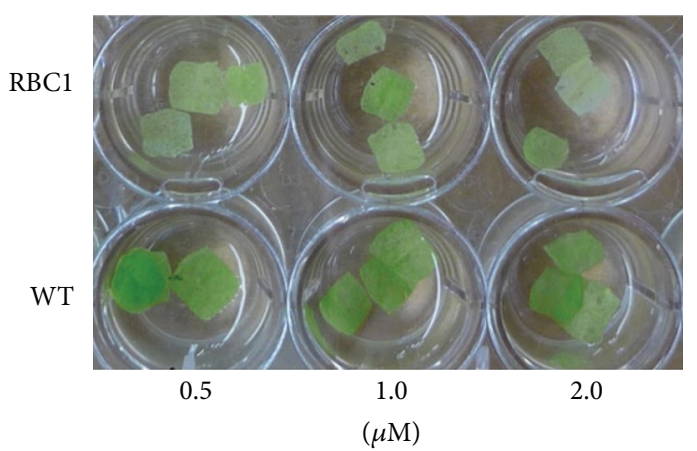

(b)

FIGURE 3: Phenotypes of an Arabidopsis overexpressed a gene encoding a MRP under normal physiological condition (a) and under a paraquat leaf disc assay (b). WT, wild type control; RBC1, Arabidopsis plant overexpressed At3g55240 gene.

identified all AtMRPs targeted to either chloroplast or mitochondria (Table S1). Among 121 AtMRPs, 21 were predicted to target chloroplast by either ChloroP or pSORT or both; 9 were predicted to localize to mitochondria by either pSORT or CELLO or both.

In conclusion, as a complementary approach to other studies on the identification of targets of Met oxidation and reduction in plants, here we found a large number of MRPs involved in important cellular processes such as RNA transcription control and calcium signaling. Several genes encoding these MRPs were transcriptionally responsive to abiotic stresses, such as drought and high salinity, suggesting their roles in the adaptation of plants to these stressors. The fact that promoters of the genes encoding stress-responsive MRPs are slightly enriched in cis-element responsive to stresses and that product of these genes were predicted to localize in ROS-enriched organelles, chloroplast and mitochondria, further confirm their functions. Taken together, this work proposes unique evidence on methionine oxidation in proteins and its possible role in regulating the plant's activities.

\section{Competing Interests}

The authors declare that they have no competing interests.

\section{Acknowledgments}

This work was funded by the National Foundation for Science and Technology Development (NAFOSTED) under the Grant no. 106-NN.02-2013.46 to Dung Tien Le. Stephanie K. Dalquist (skd@mit.edu) is acknowledged for correcting English usage of this paper. Dung Tien Le wishes to thank Vadim Gladyshev (Harvard Medical School) and Son Tran
(RIKEN CSRS) for helpful discussions during the early phase of this study.

\section{References}

[1] E. R. Stadtman, "Oxidation of free amino acids and amino acid residues in proteins by radiolysis and by metal-catalyzed reactions," Annual Review of Biochemistry, vol. 62, pp. 797-821, 1993.

[2] E. M. Balog, L. E. Norton, R. A. Bloomquist et al., "Calmodulin oxidation and methionine to glutamine substitutions reveal methionine residues critical for functional interaction with ryanodine receptor-1," The Journal of Biological Chemistry, vol. 278, no. 18, pp. 15615-15621, 2003.

[3] N. J. Carruthers and P. M. Stemmer, "Methionine oxidation in the calmodulin-binding domain of calcineurin disrupts calmodulin binding and calcineurin activation," Biochemistry, vol. 47, no. 10, pp. 3085-3095, 2008.

[4] J. R. Erickson, M.-L. A. Joiner, X. Guan et al., "A dynamic pathway for calcium-independent activation of CaMKII by methionine oxidation," Cell, vol. 133, no. 3, pp. 462-474, 2008.

[5] B. Ezraty, R. Grimaud, M. El Hassouni, D. Moinier, and F. Barras, "Methionine sulfoxide reductases protect $\mathrm{Ffh}$ from oxidative damages in Escherichia coli," The EMBO Journal, vol. 23, no. 8, pp. 1868-1877, 2004.

[6] D. T. Le, M.-Y. Yoon, Y. T. Kim, and J.-D. Choi, "Roles of conserved methionine residues in tobacco acetolactate synthase," Biochemical and Biophysical Research Communications, vol. 306, no. 4, pp. 1075-1082, 2003.

[7] Z. Su, J. Limberis, R. L. Martin et al., "Functional consequences of methionine oxidation of hERG potassium channels," Biochemical Pharmacology, vol. 74, no. 5, pp. 702-711, 2007.

[8] H. Sun, J. Gao, D. A. Ferrington, H. Biesiada, T. D. Williams, and T. C. Squier, "Repair of oxidized calmodulin by methionine sulfoxide reductase restores ability to activate the plasma 
membrane Ca-ATPase," Biochemistry, vol. 38, no. 1, pp. 105-112, 1999.

[9] W. Vogt, "Oxidation of methionyl residues in proteins: tools, targets, and reversal," Free Radical Biology and Medicine, vol. 18, no. 1, pp. 93-105, 1995.

[10] F. Takahashi, T. Mizoguchi, R. Yoshida, K. Ichimura, and K. Shinozaki, "Calmodulin-dependent activation of MAP kinase for ROS homeostasis in Arabidopsis," Molecular Cell, vol. 41, no. 6, pp. 649-660, 2011.

[11] J. Snijder, R. J. Rose, R. Raijmakers, and A. J. R. Heck, "Sitespecific methionine oxidation in calmodulin affects structural integrity and interaction with $\mathrm{Ca}^{2+} /$ calmodulin-dependent protein kinase II," Journal of Structural Biology, vol. 174, no. 1, pp. 187-195, 2011.

[12] J. Gao, D. H. Yin, Y. Yao et al., "Loss of conformational stability in calmodulin upon methionine oxidation," Biophysical Journal, vol. 74, no. 3, pp. 1115-1134, 1998.

[13] T. Le Dung, X. Liang, D. E. Fomenko et al., "Analysis of methionine/selenomethionine oxidation and methionine sulfoxide reductase function using methionine-rich proteins and antibodies against their oxidized forms," Biochemistry, vol. 47, no. 25, pp. 6685-6694, 2008.

[14] X. Liang, A. Kaya, Y. Zhang, D. T. Le, D. Hua, and V. N. Gladyshev, "Characterization of methionine oxidation and methionine sulfoxide reduction using methionine-rich cysteine-free proteins," BMC Biochemistry, vol. 13, no. 1, article 21, 2012.

[15] D. B. Oien, T. Canello, R. Gabizon et al., "Detection of oxidized methionine in selected proteins, cellular extracts and blood serums by novel anti-methionine sulfoxide antibodies," Archives of Biochemistry and Biophysics, vol. 485, no. 1, pp. 35-40, 2009.

[16] N. B. Wehr and R. L. Levine, "Wanted and wanting: antibody against methionine sulfoxide," Free Radical Biology and Medicine, vol. 53, no. 6, pp. 1222-1225, 2012.

[17] L. Tarrago, S. Kieffer-Jaquinod, T. Lamant et al., "Affinity chromatography: a valuable strategy to isolate substrates of methionine sulfoxide reductases?" Antioxidants and Redox Signaling, vol. 16, no. 1, pp. 79-84, 2012.

[18] B. Ghesquière, V. Jonckheere, N. Colaert et al., "Redox proteomics of protein-bound methionine oxidation," Molecular \& Cellular Proteomics, vol. 10, no. 5, Article ID M110.006866, 2011.

[19] S. Jacques, B. Ghesquière, P.-J. De Bock et al., "Protein methionine sulfoxide dynamics in Arabidopsis thaliana under oxidative stress," Molecular and Cellular Proteomics, vol. 14, no. 5, pp. 12171229, 2015.

[20] A. Koc, A. P. Gasch, J. C. Rutherford, H.-Y. Kim, and V. N. Gladyshev, "Methionine sulfoxide reductase regulation of yeast lifespan reveals reactive oxygen species-dependent and independent components of aging," Proceedings of the National Academy of Sciences of the United States of America, vol. 101, no. 21, pp. 7999-8004, 2004.

[21] D. T. Le, B. C. Lee, S. M. Marino et al., "Functional analysis of free methionine-R-sulfoxide reductase from Saccharomyces cerevisiae," Journal of Biological Chemistry, vol. 284, no. 7, pp. 4354-4364, 2009.

[22] H. Ruan, X. D. Tang, M.-L. Chen et al., "High-quality life extension by the enzyme peptide methionine sulfoxide reductase," Proceedings of the National Academy of Sciences of the United States of America, vol. 99, no. 5, pp. 2748-2753, 2002.

[23] J. Moskovitz, S. Bar-Noy, W. M. Williams, J. Requena, B. S. Berlett, and E. R. Stadtman, "Methionine sulfoxide reductase (MsrA) is a regulator of antioxidant defense and lifespan in mammals," Proceedings of the National Academy of Sciences of the United States of America, vol. 98, no. 23, pp. 12920-12925, 2001.

[24] H. M. Romero, B. S. Berlett, P. J. Jensen, E. J. Pell, and M. Tien, "Investigations into the role of the plastidial peptide methionine sulfoxide reductase in response to oxidative stress in Arabidopsis," Plant Physiology, vol. 136, no. 3, pp. 3784-3794, 2004.

[25] S.-K. Oh, K.-H. Baek, E. S. Seong et al., "CaMsrB2, pepper methionine sulfoxide reductase $\mathrm{B} 2$, is a novel defense regulator against oxidative stress and pathogen attack," Plant Physiology, vol. 154, no. 1, pp. 245-261, 2010.

[26] C.-W. Li, S.-H. Lee, P.-S. Chieh, C.-S. Lin, Y.-C. Wang, and M.-T. Chan, "Arabidopsis root-abundant cytosolic methionine sulfoxide reductase B genes MsrB7 and MsrB8 are Involved in tolerance to oxidative stress," Plant and Cell Physiology, vol. 53, no. 10, pp. 1707-1719, 2012.

[27] E. Laugier, L. Tarrago, A. Courteille et al., "Involvement of thioredoxin y2 in the preservation of leaf methionine sulfoxide reductase capacity and growth under high light," Plant, Cell and Environment, vol. 36, no. 3, pp. 670-682, 2013.

[28] E. Laugier, L. Tarrago, C. Vieira Dos Santos, F. Eymery, M. Havaux, and P. Rey, "Arabidopsis thaliana plastidial methionine sulfoxide reductases B, MSRBs, account for most leaf peptide MSR activity and are essential for growth under environmental constraints through a role in the preservation of photosystem antennae," The Plant Journal, vol. 61, no. 2, pp. 271-282, 2010.

[29] S.-H. Lee, C.-W. Li, K. W. Koh et al., "MSRB7 reverses oxidation of GSTF2/3 to confer tolerance of Arabidopsis thaliana to oxidative stress," Journal of Experimental Botany, vol. 65, no. 17, pp. 5049-5062, 2014.

[30] T. Ichikawa, M. Nakazawa, M. Kawashima et al., "The FOX hunting system: an alternative gain-of-function gene hunting technique," Plant Journal, vol. 48, no. 6, pp. 974-985, 2006.

[31] A. Tiessen, P. Pérez-Rodríguez, and L. Delaye-Arredondo, "Mathematical modeling and comparison of protein size distribution in different plant, animal, fungal and microbial species reveals a negative correlation between protein size and protein number, thus providing insight into the evolution of proteomes," BMC Research Notes, vol. 5, article 85, 2012.

[32] J. Zhang, "Protein-length distributions for the three domains of life," Trends in Genetics, vol. 16, no. 3, pp. 107-109, 2000.

[33] O. Thimm, O. Bläsing, Y. Gibon et al., "MAPMAN: a userdriven tool to display genomics data sets onto diagrams of metabolic pathways and other biological processes," Plant Journal, vol. 37, no. 6, pp. 914-939, 2004.

[34] R. Nishiyama, D. T. Le, Y. Watanabe et al., "Transcriptome analyses of a salt-tolerant cytokinin-deficient mutant reveal differential regulation of salt stress response by cytokinin deficiency," PLoS ONE, vol. 7, no. 2, Article ID e32124, 2012.

[35] R. Nishiyama, Y. Watanabe, M. A. Leyva-Gonzalez et al., "Arabidopsis AHP2, AHP3, and AHP5 histidine phosphotransfer proteins function as redundant negative regulators of drought stress response," Proceedings of the National Academy of Sciences of the United States of America, vol. 110, no. 12, pp. 4840-4845, 2013.

[36] D. T. Le, R. Nishiyama, Y. Watanabe et al., "Differential gene expression in soybean leaf tissues at late developmental stages under drought stress revealed by genome-wide transcriptome analysis," PLoS ONE, vol. 7, no. 11, Article ID e49522, 2012.

[37] O. Emanuelsson, H. Nielsen, S. Brunak, and G. von Heijne, "Predicting subcellular localization of proteins based on their 
N-terminal amino acid sequence," Journal of Molecular Biology, vol. 300, no. 4, pp. 1005-1016, 2000.

[38] P. Horton, K.-J. Park, T. Obayashi et al., "WoLF PSORT: protein localization predictor," Nucleic Acids Research, vol. 35, no. 2, pp. W585-W587, 2007.

[39] C.-S. Yu, Y.-C. Chen, C.-H. Lu, and J.-K. Hwang, "Prediction of protein subcellular localization," Proteins, vol. 64, no. 3, pp. 643-651, 2006. 

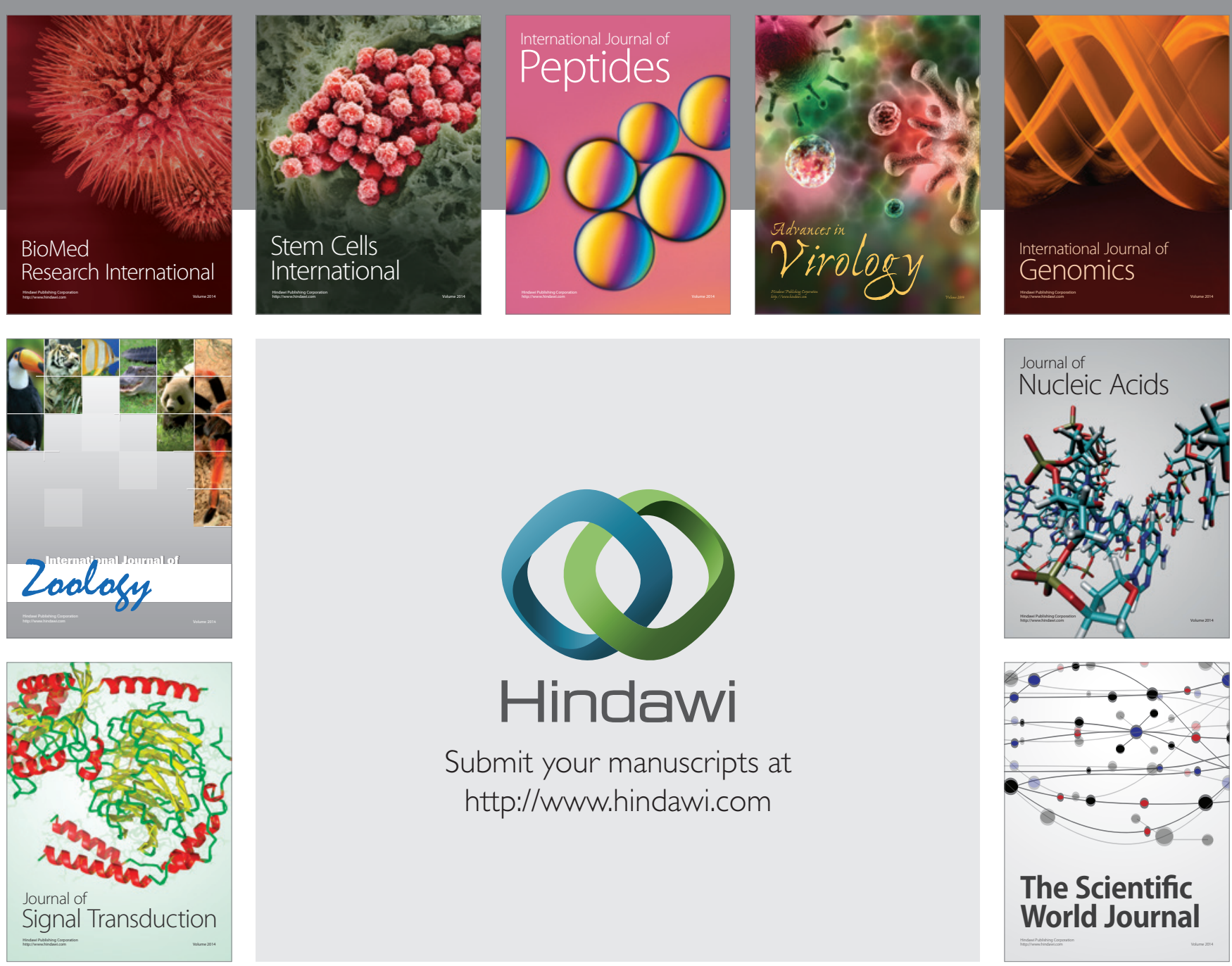

Submit your manuscripts at

http://www.hindawi.com
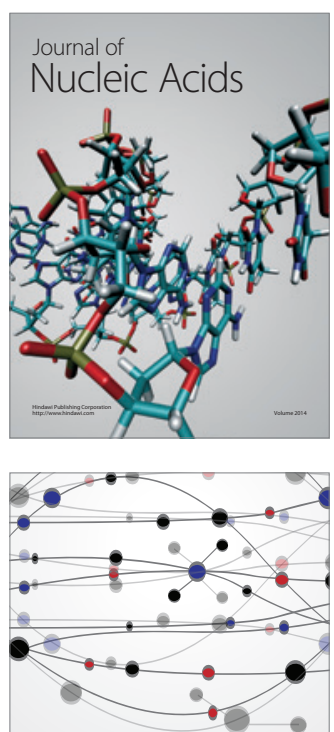

The Scientific World Journal
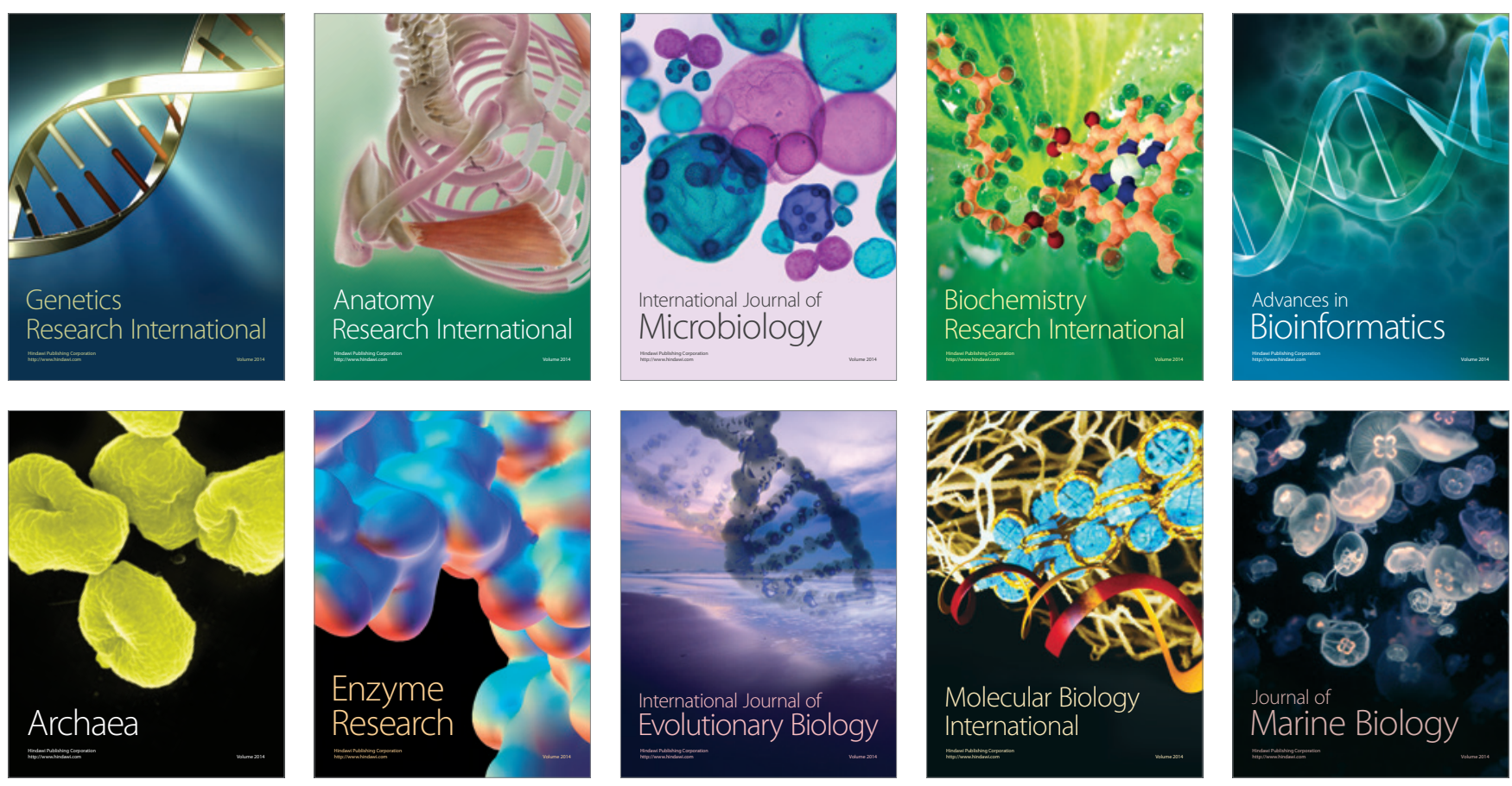